\title{
Prognostic and predictive value of IGFBP-6 in head and neck squamous cell carcinoma
}

\author{
Yue Qi ${ }^{1}$, Mingming Tang ${ }^{2}$, Wencheng Dai ${ }^{2}$, Huaiqin Zhang ${ }^{3}$, Liang Han $^{2^{*}}$ \\ ${ }^{1}$ Department of Oncologyand Clinical Bio-bank, Affiliated Hospital of Nantong University, Nantong, Jiangsu 226001, China \\ ${ }^{2}$ Department of Head and Neck Surgery, Affiliated Tumor Hospital of Nantong University, Nantong Tumor Hospital, Nantong, Jiangsu 226361, China \\ ${ }^{3}$ Department of Otolaryngology and Head and Neck Surgery, Rugao People's Hospital, Nantong, Jiangsu 226500, China
}

\begin{abstract}
The aim of this study was to assess insulin-like growth factor binding protein-6 (IGFBP-6) expression, and its potential value as a prognostic indicator of survival in patients with head and neck cancer (HNC). Quantitative realtime polymerase chain reaction (qRT-PCR) and immunohistochemistry analyses were used to determine IGFBP-6 mRNA and protein expression, respectively, in HNC. The correlations between IGFBP-6 expression levels and clinical characteristics or prognoses were determined via statistical analyses. IGFBP-6 mRNA and protein levels were significantly higher in HNC tissues than in normal adjacent tissues $(P<0.0001)$. High IGFBP-6 expression in cancer tissues was significantly associated with sex $(P=0.013)$, tobacco consumption $(P=0.021)$, tumor location $(P=0.001)$, histopathological grade $(P=0.030), \mathrm{T}$ stage $(P=0.04)$, and tumor classification. IGFBP-6 expression in buccal squamous cell carcinoma (BSCC) tissues was correlated with laryngeal squamous cell carcinoma (LSCC) development $(P=0.001)$ but not tongue squamous cell carcinoma (TSCC) development $(P=0.355)$. High IGFBP-6 expression $(P=0.001)$, histopathological grade $(P=0.020)$, T stage $(P=0.007)$, lymph node metastasis $(P=0.001)$, and pTNM stage $(P=0.001)$ were identified as significant prognostic factors for survival. Kaplan-Meier survival curves demonstrated that patients with high IGFBP-6 levels or stage III + IV cancer exhibited significantly shorter survival times than patients with low IGFBP-6 levels or stage I + II disease. Our findings provide the first evidence that high IGFBP-6 expression is associated with poor prognosis in HNC.
\end{abstract}

Keywords: head and neck cancer, insulin-like growth factor binding protein-6, immunohistochemistry, prognosis

\section{INTRODUCTION}

Head and neck cancer (HNC) is the sixth most common cancer, with approximately 700,000 new cases diagnosed each year worldwide ${ }^{[1-2]}$. Squamous cell carcinoma of the head and neck (HNSCC) is the most common pathological type. Patients who undergo complete surgical resection and several regimens of multidisciplinary treatment show improved

*Correspondence to: Liang Han, Department of Head and Neck Surgery, Affiliated Tumor Hospital of Nantong University, Nantong Tumor Hospital, Nantong 226361, Jiangsu, China. E-mail: h161697@126.com Conflict of interest:The authors declare no conflicts of interest. survival. Approximately $30 \% \sim 50 \%$ of patients with HNC survive more than 5 years after their initial diagnoses ${ }^{[3]}$. However, two-thirds of patients with SCCHN present with advanced disease characterized by regional lymph node metastasis at the time of their initial diagnosis, and $10 \%$ of patients present with distant metastasis ${ }^{[4]}$. Currently available systemic therapies are usually insufficient for controlling tumors in these patients, whose prognoses are poor. Therefore, it is important to develop new approaches for targeting this aggressive and highly resistant type of cancer.

The insulin-like growth factor (IGF) pathway is a major regulator of physiological growth in mammals, and a family of six high-affinity IGF-binding proteins 
(IGFBP1-6) modulates IGF activity ${ }^{[5]}$. IGFBP-6 is a $30 \mathrm{kDa}, \mathrm{O}$-glycosylated protein which exhibits a binding affinity for IGF- II that is 50 -fold higher than its binding affinity for IGF-I. Moreover, IGFBP-6 inhibits IGFII activity, but has little effect on IGF-I activity ${ }^{[6]}$. This specificity makes IGFBP-6 an attractive therapeutic target for treating IGF- II -dependent malignancies, such as rhabdomyosarcoma (RMS), neuroblastoma, colon cancerand ovarian cancer. Indeed, IGFBP-6 was shown to inhibit anchorage-dependent and anchorageindependent RMS cell proliferation and promote RMS cell apoptosis in vitro ${ }^{[7]}$. It reported that IGFBP-6 can inhibit cell proliferation by IGF- II sequestration and the reduction of proteolysis in neuroblastoma ${ }^{[8]}$. In colon cancer, increased concentrations of IGFBP-6 decrease cellular proliferation via an indirect mechanism that prevents IGF- II from interacting with the IGF-I receptor ${ }^{[9]}$. Some articles showed that IGFBP-6 expression in vascular endothelial cells is up-regulated by hypoxia-induced HIF-l activation, leading to a decrease in angiogenesis in vitro and in vivo ${ }^{[10]}$. Furthermore, IGFBP-6 down-regulation is associated with adrenocorticotrophic hormone-secreting pituitary adenoma growth, via activation of the PI3K-AKTmTOR pathway ${ }^{[11]}$.

Some studies have identified IGFBP- 6 as a proliferation-related gene in $\mathrm{HNSCC}$, and the down-regulation of IGFBP6 in nodal metastasis compared with primary tumors ${ }^{[12]}$. Knockdown of FUCAl and treatment with IGFBP6 inhibited the migration of OECM-1 cells ${ }^{[13]}$. Furthermore, IGFBP- 6 has been found to promote cell migration by p38 MAPK and crosstalk with other MAPKs on an IGF-independent way in cancer ${ }^{[14-15]}$. To date, there have been no reports examining IGFBP- 6 expression and its clinical significance in different tumor classifications of HNSCC. In this study, we compared IGFBP-6 expression levels in buccal squamous cell carcinoma (BSCC), laryngeal squamous cell carcinoma (LSCC) and tongue squamous cell carcinoma (TSCC) with those in adjacent tissues and examined the correlations between IGFBP-6 levels and patient prognoses. Our results demonstrate the prognostic significance of IGFBP-6 expression in HNC and suggest that this marker may be a prognostic indicator of survival in patients with $\mathrm{HNC}$.

\section{MATERIALS AND METHODS}

\section{Patients and tissue microarray analysis (TMA)}

A total of 312 formalin-fixed, paraffin-embedded tumor samples, including 112 TSCC, 84 BSCC and 116 LSCC samples, and matched adjacent tissue specimens were obtained from patients who under- went surgeryat the Affiliated Hospital of Nantong University, China, between January 2002 and December 2013.

Clinical data, including information regarding age, sex, tobacco consumption, alcohol consumption, tumor location, tumor classification, histological type, $\mathrm{T}$ stage and lymph node metastasis status were acquired from patient medical records. None of the patients enrolled in this study had received neoadjuvant immunotherapy, radiotherapy or chemotherapy prior to surgery. The 5-year overall survival rate was calculated by using the interval between the date of surgery and the date of death or the last follow-up appointment. Written informed consent was obtained from each subject. The study protocol was approved by the Ethics Committee of the Affiliated Hospital of Nantong University, and all experiments were performed in accordance with the approved guidelines of the Affiliated Hospital of Nantong University. All procedures performed in studies involving human participants were in accordance with the ethical standards of the institutional and national research committee and with the 1964 Helsinki declaration and its later amendments or comparable ethical standards. Informed consent was obtained from all individual participants included in the study.

TMAs were manufactured aspreviously described ${ }^{[16]}$. Representative cancerous regions were labeled in the paraffin blocks in accordance with the results of hematoxylin and eosin staining (H\&E). Tissue samples (2 mm in diameter) were produced using a tissue arraying instrument (Quick-Ray, UT06; UNITMA, Korea) and sequentially aligned into prepared blank paraffin blocks. H\&E staining was also performed for qualitative analyses of the TMA sections.

\section{Quantitative real-time polymerase chain re- action (qRT-PCR)}

Fifty-six fresh-frozen tissue samples, including 28 cancer tissue samples and 28 matched adjacent normal tissues, were obtained from the Affiliated Hospital of Nantong University. Total RNA was extracted from these frozen samples using TRIzol reagent (Invitrogen, Carlsbad, CA, USA) and was reverse transcribed into cDNA using a Revert Aid ${ }^{\mathrm{TM}}$ First Strand cDNA Synthesis Kit (Fermentas, Glen Burnie, MD, USA) according to the manufacturer's instructions. The housekeeping gene encoding glyceraldehyde-3-phosphate dehydrogenase (GAPDH) was run in parallel and used to normalize IGFBP-6 gene expression. The following RT-PCR primers were used: IGFBP- 6 forward primer: 5'-GGAGAATCCTAAGGAGAGTA-3' and reverse primer: 5'- ATTCCTCTGTTGGTCTCT-3' (San- 
gon; Shanghai, China); and GAPDH forward primer: 5'-TGCACCACCAACTGCTTA GC-3' and reverse primer: 5'-GGC ATG GACTGTGGTCATGAG-3'. Reverse transcription and Taq activation were performed via the following sequential incubation steps: $30 \mathrm{~min}$ at $42^{\circ} \mathrm{C}$ and $2 \mathrm{~min}$ at $94^{\circ} \mathrm{C}$. Amplification comprised the following steps: 35 cycles at $95^{\circ} \mathrm{C}$ for $20 \mathrm{~s}, 56^{\circ} \mathrm{C}$ for $20 \mathrm{~s}$, and $72^{\circ} \mathrm{C}$ for $30 \mathrm{~s}$. All experiments were performed in triplicate.

\section{Immunohistochemical staining and analysis}

Immunohistochemical staining for IGFBP-6 was performed as previously described ${ }^{[17]}$. Before immunohistochemical processing, the TMA specimens were cut into 4- $\mu \mathrm{m}$ sections and placed on Superfrost charged glass microscope slides before being deparaffinized, rehydrated, and subjected to antigen retrieval and blocking via non-specific binding. The tissue samples were then incubated with primary rabbit anti-IGFBP-6 antibodies (1:500, Abcam, Cambridge, MA), and this was followed by incubation with Envision goat antirabbit HRP secondary antibodies (DAKO, Carpinteria, CA). The slides were evaluated by two trained pathologists who were blinded to the research objectives.

The IGFBP-6 expression cutoff value that was statistically significant with respect to survival was obtained using the X-tile software program (Rimm Lab, Yale University; http://medicine.yale.edu/lab/ rimm/links/). IGFBP-6 staining intensity was scored on a scale using a two-level grading system (negative or weak intensity-strong intensity). The final staining scores were defined as follows: 0-90, low or no expression; 91-300, high expression.

\section{Statistical analysis}

Chi-square testswere used to analyze the associations between clinic pathological variables and IGFBP-6 protein expression. Wilcoxon signed rank nonparametric tests were used to compare IGFBP- 6 mRNA expression levels in fresh-frozen tissues with those in matched adjacent tissues. The log-rank test and Kaplan-Meier method were used to calculate survival curves. A multivariate Cox regression model was used to evaluate the significant prognostic factors in the univariate model. $P<0.05$ was considered statistically significant. All data were analyzed using STATA 9.0 software (Stata Corporation, College Station, TX).

\section{RESULTS}

\section{IGFBP-6 mRNA expression in HNSCC and adjacent tissues}

IGFBP-6 mRNA expression levels in HNSCC tis- sues and matched adjacent tissues were analyzed by qRT-PCR. IGFBP-6 mRNA levels were significantly higher in cancer tissues than inmatched adjacent tissues $(0.3729 \pm 0.0324$ vs. $0.1400 \pm 0.0131$, $P<0.0001$, Fig.1).

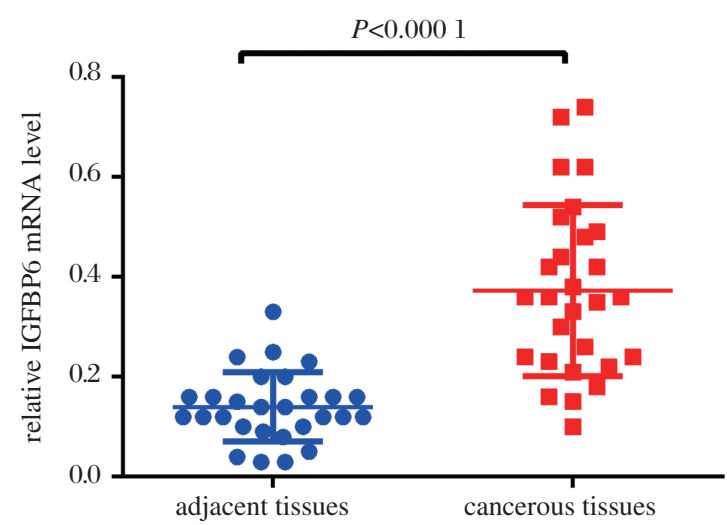

Fig. 1 IGFBP-6 mRNA levels were significantly higher in HNSCC tissues than in adjacent normal tissues. IGFBP-6 mRNA levels were determined via qRT-PCR and normalized to GAPDH mRNA levels.

\section{IGFBP-6 protein expression in $\mathrm{HNC}$ and peri- tumoral tissues}

To study IGFBP-6 protein expression in carcinoma tissues and matched adjacent tissues, we performed immunohistochemical analyses to detect IGFBP-6 protein expression in TSCC, BSCC and LSCC tissues and matched non-cancer tissues. As shown in Fig.2, higher IGFBP-6 expression levels were detected in cancer tissues than in adjacent matched tissues. Specifically, $37.5 \%(42 / 112)$ of TSCC tissue samples $\left(\chi^{2}=12.262, P<0.001\right), 44 \%$ (37/84) of BSCC tissue samples $\left(\chi^{2}=16.563, P<0.001\right)$ and $61.2 \%(71 / 116)$ of LSCC tissue samples $\left(\chi^{2}=35.221, P<0.001\right)$ exhibited high IGFBP-6 expression, whereas $9.1 \%, 7.5 \%$, and $10.4 \%$ of TSCC, BSCC and LSCC peritumoral tissue samples, respectively, exhibited high IGFBP-6 expression (Table 1).

\section{Relationship between IGFBP-6 protein levels and clinical parameters}

We subsequently analyzed the relationships between IGFBP-6 protein levels and patient clinicopathological parameters, which are shown in Table 2. High IGFBP-6 levels in cancer tissues were significantly associated with sex $(P=0.013)$, tobacco consumption $(P=0.021)$, tumor location $(P<0.001)$, histopathological grade $(P=0.030)$, T stage $(P=0.040)$ and tumor classification. Additionally, IGFBP-6 expression in BSCC tissues was correlated with LSCC development $(P<0.001)$ but not TSCC development $(P=0.355)$. However, we observed no significant associations between IGFBP-6 

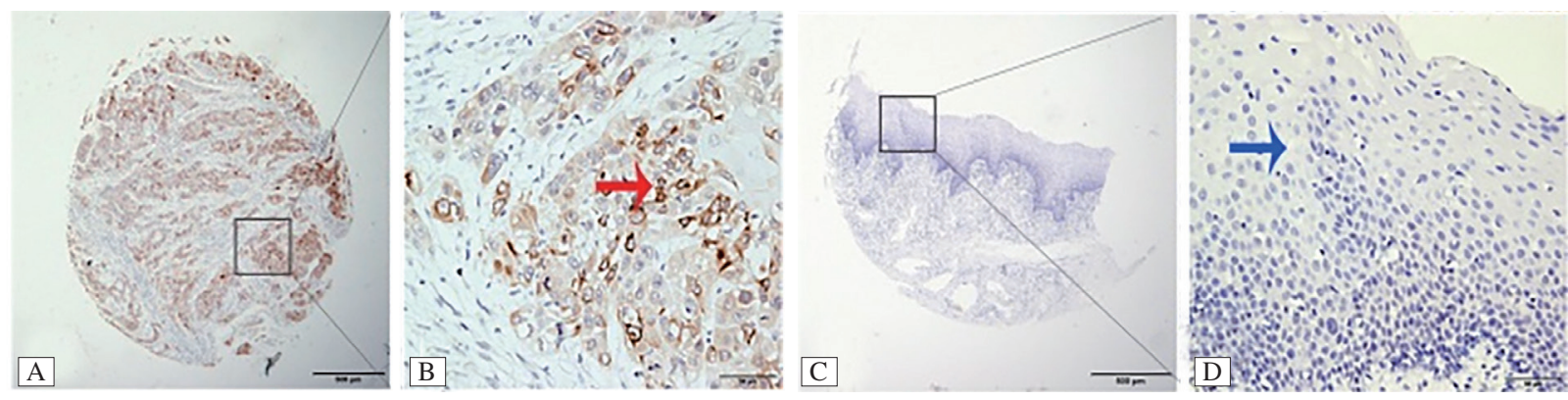

Fig. 2 IGFBP-6 protein expression was detected in HNSCC tissues but not in adjacent normal tissues. IGFBP-6 protein expression was determined by TMA immunohistochemistry; A、B: HNSCC tissues, positive for IGFBP-6 protein expression; C、 D: adjacent normal tissues, negative for IGFBP- 6 protein expression. A and B are shown at $\times 40$ magnification (bar=500 $\mu \mathrm{m}$ ), and $\mathrm{C}$ and D are shown at $\times 400$ magnification (bar $=50 \mu \mathrm{m}$ ). The red arrows indicate IGFBP-6 protein expression in the cytoplasm of epithelial cancer cells, and the green arrows indicate no IGFBP-6 protein expression in adjacent normal tissues.

Table 1 IGFBP-6 protein expression in TSCC, BSCC and LSCC tissue samples and matched adjacent normal tissue samples

\begin{tabular}{|c|c|c|c|c|c|c|}
\hline \multirow{2}{*}{\multicolumn{2}{|c|}{ Groups }} & \multirow[b]{2}{*}{$n$} & \multicolumn{2}{|c|}{ IGFBP-6 expression } & \multirow[b]{2}{*}{$\chi^{2}$} & \multirow[b]{2}{*}{$P$ value } \\
\hline & & & $\begin{array}{c}\text { High expression } \\
{[n(\%)]}\end{array}$ & $\begin{array}{c}\text { Low expression } \\
{[n(\%)]}\end{array}$ & & \\
\hline \multirow[t]{2}{*}{ TSCC } & cancer tissues & 112 & $42(37.5)$ & $70(62.5)$ & & \\
\hline & matched non-cancer tissues & 44 & $4(9.1)$ & $40(90.9)$ & 12.262 & $<0.001$ \\
\hline \multirow[t]{2}{*}{ BSCC } & cancer tissues & 84 & $37(44.0)$ & $47(56.0)$ & & \\
\hline & matched non-cancer tissues & 40 & $3(7.5)$ & $37(92.5)$ & 16.563 & $<0.001$ \\
\hline \multirow[t]{2}{*}{ LSCC } & cancer tissues & 116 & $71(61.2)$ & $45(38.8)$ & & \\
\hline & matched non-cancer tissues & 48 & $5(10.4)$ & $43(89.4)$ & 35.221 & $<0.001$ \\
\hline
\end{tabular}

levels and other clinicopathological characteristics, such as age, alcohol consumption, lymph node metastasis and PTNM stage.

\section{High IGFBP-6 expression is predictive of poor prognosis}

As determined via univariate Cox regression analyses, high IGFBP-6 expression $(P=0.001)$, histopathological grade $(P=0.020)$, T stage $(P=0.007)$, lymph node metastasis $(P=0.001)$, and pTNM stage $(P=0.001)$ were significant prognostic factors for survival (Table 3). The multivariate Cox proportional hazards regression model demonstrated that high IGFBP-6 expression $(P=0.002)$ and pTNM stage $(P<0.001)$ were the strongest predictors of survival (Table 3). KaplanMeier survival curves demonstrated that patients with high IGFBP-6 levels or stage III + IV tumors exhibited significantly shorter survival times than patients with low IGFBP-6 levels or stage I + II tumors (Fig.3).

\section{DISCUSSION}

In this study, we found that IGFBP-6 mRNA and protein expression was significantly higher in HNSCC tissues than in adjacent normal tissues by qRT-PCR and immunohistochemistry. High IGFBP-6 expression $(P=0.002)$ and pTNM stage $(P<0.001)$ were the strongest predictors of survival. Interestingly, IGFBP-6 levels were higher in men than in women, which may be due to sex related steroid effects on IGFBP-6 ${ }^{[18]}$. IGFBP-6 expression has been linked to tobacco consumption, which is one of the most important risk factors for $\mathrm{HNC}^{[19]}$. We also observed an association between IGFBP- 6 expression and tobacco consumption. These demonstrated that IGFBP-6 plays an important role in HNC development. Recent studies have shown that IGFBP-6 dysregulation plays a role in tumorigenesis by inducing alternations in $\beta$-catenin transcription ${ }^{[20]}$, hypoxia ${ }^{[10]}$, P53 transcription ${ }^{[21]}$, sex steroids $^{[22]}$, and TGF- $\beta$ transcription ${ }^{[23]}$. IGFBP-6 expression has been detected in several cancer cells and models, including IGF2-dependent tumors, such as RMS, neuroblastoma and colon cancer.

IGFBPs, which comprise of three structural domains of approximately equalsize, have been shown to inhibit IGF activity by competing with the IGF-I receptor (IGFIR), thereby preventing IGFIR binding ${ }^{[24]}$. Under specific conditions, several IGFBPs may enhance IGF activity ${ }^{[25]}$. The IGFBP superfamily can prolong IGF half-lives, enhance IGF-dependent metabolic clearance, and coordinate and regulate a variety of biological activities ${ }^{[26-28]}$. IGFBPs are involved in physiological growth and are also associated with several 
Table 2 Associations between IGFBP-6 expression and HNSCC clinical parameters

\begin{tabular}{|c|c|c|c|c|c|}
\hline \multirow[b]{2}{*}{ Groups } & \multirow[b]{2}{*}{$n$} & \multicolumn{2}{|c|}{ IGFBP-6 expression } & \multirow[b]{2}{*}{$\chi^{2}$} & \multirow[b]{2}{*}{$P$ value } \\
\hline & & $\begin{array}{c}\text { High expression } \\
{[\mathrm{n}(\%)]}\end{array}$ & $\begin{array}{c}\text { Low expression } \\
{[\mathrm{n}(\%)]}\end{array}$ & & \\
\hline Total & 312 & $150(48.1)$ & $162(51.9)$ & & \\
\hline Age (years) & & & & 1.417 & 0.234 \\
\hline$\leq 60 \mathrm{y}$ & 123 & $54(43.9)$ & $69(56.1)$ & & \\
\hline$>60 y$ & 189 & $96(50.8)$ & $93(49.2)$ & & \\
\hline Sex & & & & 6.213 & 0.013 \\
\hline Female & 107 & $41(38.3)$ & $66(61.7)$ & & \\
\hline Male & 205 & $109(53.2)$ & 96 (46.8) & & \\
\hline Tobacco consumption & & & & 5.326 & 0.021 \\
\hline Yes & 65 & $41(63.1)$ & $24(36.9)$ & & \\
\hline No & 179 & $83(46.4)$ & $96(53.6)$ & & \\
\hline Unknown & 68 & & & & \\
\hline Alcohol consumption & & & & 3.761 & 0.052 \\
\hline Yes & 122 & $53(43.4)$ & $69(56.6)$ & & \\
\hline No & 135 & $75(55.6)$ & $60(44.4)$ & & \\
\hline Unknown & 55 & & & & \\
\hline Tumor location & & & & 12.752 & $<0.001$ \\
\hline Oral & 196 & $79(40.3)$ & $117(59.7)$ & & \\
\hline Larynx & 116 & $71(61.2)$ & 45 (38.8) & & \\
\hline Tumor classification & & & & $0.885 \triangle$ & 0.355 \\
\hline TSCC & 112 & $42(37.5)$ & $70(62.5)$ & & \\
\hline BSCC & 84 & $37(44.0)$ & $47(56.0)$ & $13.577 \nabla$ & $<0.001$ \\
\hline LSCC & 116 & $71(61.2)$ & 45 (38.8) & & \\
\hline Histopathological grade & & & & 7.015 & 0.030 \\
\hline High & 166 & $70(42.2)$ & $96(57.8)$ & & \\
\hline Moderate & 121 & $70(57.9)$ & $51(42.1)$ & & \\
\hline Low & 13 & $7(53.8)$ & $6(46.2)$ & & \\
\hline Unknown & 12 & & & & \\
\hline T stage & & & & 4.236 & 0.040 \\
\hline $\mathrm{T} 1+\mathrm{T} 2$ & 214 & $103(48.1)$ & $111(51.9)$ & & \\
\hline $\mathrm{T} 3+\mathrm{T} 4$ & 36 & $24(66.7)$ & $12(33.3)$ & & \\
\hline Unknown & 62 & & & & \\
\hline Lymph node metastasis & & & & 0.013 & 0.910 \\
\hline Yes & 61 & $31(50.8)$ & $30(49.2)$ & & \\
\hline No & 218 & $109(50.0)$ & $109(50.0)$ & & \\
\hline Unknown & 33 & & & & \\
\hline pTNM stage & & & & 1.062 & 0.303 \\
\hline Stage $I+I$ & 167 & $81(48.5)$ & $86(51.5)$ & & \\
\hline Stage $I I I+I V$ & 83 & $46(55.4)$ & $37(44.6)$ & & \\
\hline Unknown & 62 & & & & \\
\hline
\end{tabular}

$\triangle$ Correlation between IGFBP-6 expression in TSCC and IGFBP-6 expression in BSCC. $\nabla$ Correlation among IGFBP-6 expression in TSCC, IGFBP-6 expression in BSCC and IGFBP-6 expression in LSCC.

diseases, including cancer ${ }^{[29]}$. IGFBP-6 is a member of a family of six high-affinity IGFBPs and has been shown to function as an IGF2-dependent and IGF2independent onco-suppressor gene ${ }^{[30,31]}$.

HNCs comprise of a variety of malignant neoplasms occurring at different sites within the upper aero-digestive tract, such as the oropharynx, hypopharynx, larynx and tongue $^{[4]}$. Adrenocortical cancer studies have found that several IGF-related genes (IGF2, IGF2R, IGFBP3 and IGFBP-6) are significantly up-regulated in adrenocortical carcinomas $^{[32]}$. Thus, IGFBP-6 expression may play an important role in maintaining tumor cell proliferation and preventing tumor cell differentiation. However, IGFBP-6 levels may be lower in malignant cells than in normal cells, thus suggesting that IGFBP-6 exerts inhibitory effects in some tumors. In RMS research, IGFBP-6 inhibited proliferation and promoted apoptosis of RMS cells in vitro, and dramatically inhibited xenograft growth in vivo, at least in part, by inhibiting IGF- II ${ }^{[7]}$. Moreover, the addition of IGF- II did not negate the IGFBP-6 apoptosis-promoting effect ${ }^{[33]}$. Furthermore, IGFBP-6 interacts with Ku80, which is 
122 Prognostic and predictive value of IGFBP-6 in head and neck squamous cell carcinoma, 2018, 2(2)

Table 3 Univariate and multivariate analyses of the prognostic factors for overall survival in HNSCC

\begin{tabular}{|c|c|c|c|c|c|c|}
\hline \multirow{2}{*}{ prognostic factors } & \multicolumn{3}{|c|}{ univariate analyses } & \multicolumn{3}{|c|}{ multivariate analyses } \\
\hline & HR & $P$ value & $95 \%$ CI & HR & $P$ value & $95 \%$ CI \\
\hline \multicolumn{7}{|l|}{ IGFBP6 expression } \\
\hline \multicolumn{7}{|l|}{ Age (years) } \\
\hline $60 \mathrm{y}$ vs. $>60 \mathrm{y}$ & 1.462 & 0.127 & $0.898-2.380$ & & & \\
\hline \multicolumn{7}{|l|}{ Sex } \\
\hline Female vs. Male & 1.442 & 0.163 & $0.863-2.410$ & & & \\
\hline \multicolumn{7}{|l|}{ Tobacco consumption } \\
\hline Yes vs. No & 1.200 & 0.476 & $0.727-1.982$ & & & \\
\hline \multicolumn{7}{|l|}{ Alcohol consumption } \\
\hline Yes vs. No & 0.922 & 0.737 & $0.574-1.481$ & & & \\
\hline \multicolumn{7}{|l|}{ Tumor location } \\
\hline Oral vs.Larynx & 1.248 & 0.348 & $0.786-1.983$ & & & \\
\hline \multicolumn{7}{|l|}{ Histopathological grade } \\
\hline High vs. Moderate vs. Low & 1.533 & 0.020 & $1.069-2.198$ & 1.338 & 0.129 & $0.919-1.947$ \\
\hline \multicolumn{7}{|l|}{ T stage } \\
\hline $\mathrm{T} 1+\mathrm{T} 2$ vs. $\mathrm{T} 3+\mathrm{T} 4$ & 2.070 & 0.007 & $1.216-3.524$ & 0.560 & 0.056 & $0.309-1.014$ \\
\hline \multicolumn{7}{|l|}{ Lymph node metastasis } \\
\hline Yes vs. No & 5.543 & 0.001 & $3.498-8.782$ & & & \\
\hline \multicolumn{7}{|l|}{ pTNM stage } \\
\hline Stage I $+\mathbb{I} v s$. Stage $I I+I V$ & 4.731 & 0.001 & $2.943-7.606$ & 5.763 & $<0.001$ & $3.398-9.773$ \\
\hline
\end{tabular}

$\mathrm{A}$

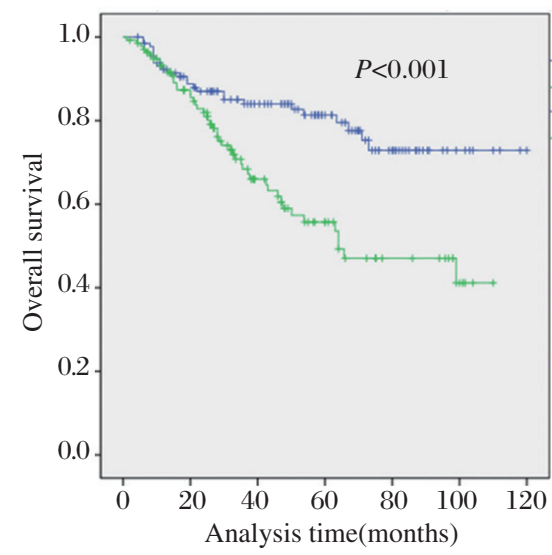

B

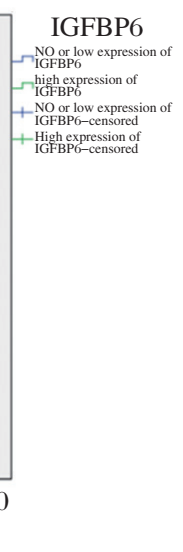

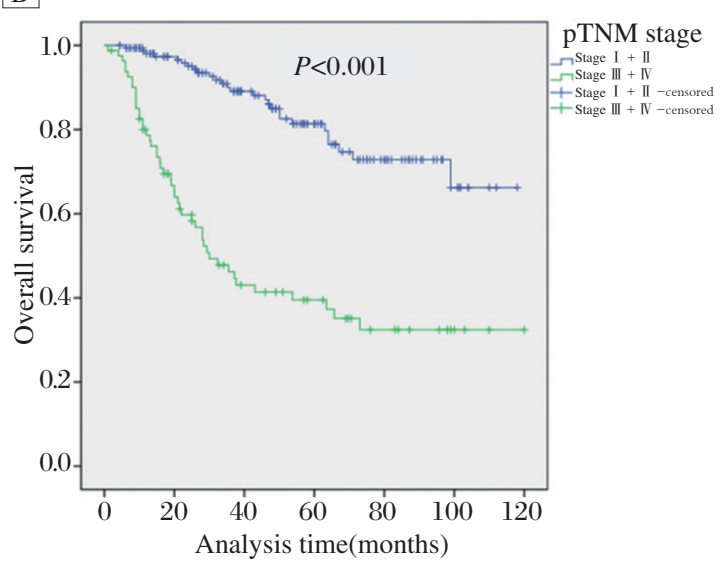

Fig. 3 HNSCC patient survival curves generated via the Kaplan-Meier method and analyzed by the log-rank test. A: IGFBP- $6^{+}$ HNSCC patients (green line) exhibited significantly poorer overall survival than IGFBP- $6^{-}$patients (blue line); B: HNSCC patients with pTNM stage III + IV disease (green line) exhibited significantly poorer overall survival than patients with pTNM stage I + II disease (blue line).

involved in DNA repair and stability ${ }^{[34]}$. In a lung cancer study involving mice, IGFBP-6 levels were lower in lung adenoma and adenocarcinoma tissues than in normal lung tissues ${ }^{[35]}$. In addition, many studies have shown that IGFBP-6 levels are decreased in other cancers, such as neuroblastoma, prostate cancer and colon cancer $^{[36-38]}$. However, two studies on ovarian cancer have yielded discrepant results:one study reported increased serum IGFBP- 6 levels ${ }^{[39]}$, and the other study reported decreased IGFBP-6 levels ${ }^{[40]}$. Notably, IGFBP-6 has been reported to be down-regulated in nasopharyngeal cancer cells and to regulate the expression of the transcription factor EGR-1, thereby acting as a tumor suppressor gene ${ }^{[31]}$. Both cell apoptosis and IGFBP-6 expression are increased by JNK activation and NF- $\kappa \mathrm{B}$ (nuclear factor $\kappa \mathrm{B}$ ) inhibition in oral cancer cells ${ }^{[41]}$. However, the direct effect of IGFBP-6 on apoptosis in these cells was not studied. In our study, we observed high levels of IGFBP-6 expression in TSCC, BSCC and LSCC, which is consistent with the results described above. We found high expression of IGFBP-6 in some sites of HNC, suggesting that increased IGFBP- 6 could represent a compensatory response to increased IGF- II activity,or it may reflect IGF-independent actions ${ }^{[18]}$.

Together, our findings indicate that IGFBP-6 may 
act as a tumor oncogene in human BSCC, LSCC and TSCC. Additionally, IGFBP-6 expression in BSCC tissues was correlated with LSCC development, but not TSCC development, indicating that its expression may be affected by different tumor microenvironments. Elucidating the mechanism underlying these interactions will require further research. Our present investigation also revealed that in addition to IGFBP-6 expression, positive lymph node metastasis may also be used as a prognostic factor for HNC.

This study demonstrated that IGFBP-6 expression was associated with $\mathrm{HNC}$ and examined the clinical significance of IGFBP-6 expression in HNC. Further studies are needed to confirm the effects of IGFBP- 6 at the cell and animal levels and to explore the molecular mechanisms underlying its biological functions. In particular, studies elucidating the mechanisms underlying the involvement of IGFBP-6 in HNC will be carried out in the near future.

In summary, we conclude that IGFBP-6 may be useful as a prognostic factor for HNCSS, and that IGFBP-6 may also be a novel therapeutic target in patients with HNCSS.

\section{Acknowledgements}

This study was funded by the Science and Technique Development Fund of Nantong (MS22015108), Jiangsu, China.

\section{References}

[1] Wang C, Dickie J, Sutavani RV, et al. Targeting Head and Neck Cancer by Vaccination[J]. Front Immunol, 2018, 9: 830

[2] Ferlay J, Soerjomataram I, Dikshit R, et al. Cancer incidence and mortality worldwide: sources, methods and major patterns in GLOBOCAN 2012[J].Int J Cancer,2015,136(5):E359-E386

[3] Abrahão R, Anantharaman D, Gaborieau V, et al. The influence of smoking, age and stage at diagnosis on the survival after larynx, hypopharynx and oral cavity cancers in Europe: The ARCAGE study[J]. Int J Cancer,2018,143(1):32-44

[4] Aboshanif M, Kawasaki Y, Omori Y, et al. Prognostic role of regenerating gene-I in patients with stageIV head and neck squamous cell carcinoma[J]. Diagn Pathol,2016,11(1):79

[5] Baxter RC.IGF binding proteins in cancer: mechanistic and clinical insights[J]. Nat Rev Cancer,2014,14(5):329-341

[6] Bach LA, Norton RS. IGF-binding proteins--the pieces are falling into place[J]. Trends Endocrinol Metab,2005,16(5):228-234

[7] Gallicchio MA, Kneen M, Hall C, et al. Overexpression of insulin-like growth factor binding protein-6 inhibits rhabdomyosarcoma growth in vivo[J]. Int J Cancer,2001,94(5):645-651
[8] Seurin D, Lassarre C, Bienvenu G, et al. Insulin-like growth factor binding protein-6 inhibits neuroblastoma cell proliferation and tumour development[J]. Eur J Cancer,2002,38(15):2058-2065

[9] Kim EJ, Schaffer BS, Kang YH, et al. Decreased production of insulin-like growth factor-binding protein (IGFBP)- 6 by transfection of colon cancer cells with an antisense IGFBP-6 cDNA construct leads to stimulation of cell proliferation[J]. J Gastroenterol Hepatol,2002,17(5):563-570

[10] Zhang C, Lu L, Li Y, et al. IGF binding protein-6 expression in vascular endothelial cells is induced by hypoxia and plays a negative role in tumor angiogenesis[J]. Int J Cancer, 2012, 130(9):2003-2012

[11] Yang Y, Sheng M, Huang F, et al. Downregulation of insulin-like growth factor binding protein 6 is associated with ACTH-secreting pituitary adenoma growth[J].Pituitary, 2014, 17(6):505-513

[12] Jeon GA, Lee JS, Patel V, et al. Global gene expression profiles of human head and neck squamous carcinoma cell lines[J]. Int J Cancer, 2004, 112(2):249-258

[13] Liu CJ, Liu TY, Kuo LT, et al. Differential gene expression signature between primary and metastatic head and neck squamous cell carcinoma[J]. J Pathol, 2008, 214(4):489-497

[14] Fu P, Liang GJ, Khot SS, et al. Cross-talk between MAP kinase pathways is involved in IGF-independent, IGFBP6-induced $\mathrm{Rh} 30$ rhabdomyosarcoma cell migration[J]. $J$ Cell Physiol, 2010, 224(3):636-643

[15] Fu PA, Bach LA. Promotion of cancer cell migration:an insulin-like growth factor(IGF)-independent action of IGFbinding protein-6[J]. J Biol Chem, 2007, 282(31):2229822306

[16] Huang, J, Mei H. Triple-amiRNA VEGFRs inhibition in pancreatic cancer improves the efficacy of chemotherapy through EMT regulation[J]. J Control Release, 2017:1-14

[17] Huang J, Zhang J, Li H, et al.VCAMl expression correlated with tumorigenesis and poor prognosis in high grade serous ovarian cancer[J]. Am J Transl Res, 2013, 5(3):336-346

[18] Bach LA, Yang Z.Insulin-like growth factor-binding protein-6 and cancer[J]. Clin Sci (Lond), 2013, 124(4):215-229

[19] Argiris A, Eng C. Epidemiology, staging, and screening of head and neck cancer[J]. Cancer Treat Res, 2003, 114: 15-60.

[20] Denys H, Jadidizadeh A, Amini Nik S, et al. Identification of IGFBP-6 as a significantly downregulated gene by betacatenin in desmoid tumors[J]. Oncogene, 2004, 23(3):654664

[21] Vanlandingham JW, Tassabehji NM, Somers RC, et al. Expression profiling of p53-target genes in coppermediated neuronal apoptosis[J]. Neuromolecular Med, 2005, 7(4):311-324

[22] Chesik D, De Keyser J. Progesterone and dexamethasone differentially regulate the IGF-system in glial cells[J]. Neurosci Lett, 2010, 468(3):178-182

[23] Ong VH, Carulli MT, Xu S, et al. Cross-talk between MCP-3 and TGFbeta promotes fibroblast collagen 
124 Prognostic and predictive value of IGFBP-6 in head and neck squamous cell carcinoma, 2018, 2(2)

biosynthesis[J]. Exp Cell Res, 2009, 315(2):151-161

[24] Sitar T, Popowicz GM, Siwanowicz I, et al. Structural basis for the inhibition of insulin-like growth factors by insulin-like growth factor-binding proteins[J]. Proc Natl Acad Sci U S A, 2006, 103(35):13028-13033

[25] Adamek A, Kasprzak A. Insulin-Like growth factor (IGF) system in liver diseases[J]. Int J Mol Sci, 2018, 19(5): 1308

[26] Jones JI, Clemmons DR. Insulin-like growth factors and their binding proteins: biological actions[J]. Endocr Rev, 1995, 16(1):3-34

[27] Hwa VO, Rosenfeld RG. The insulin-like growth factor-binding protein(IGFBP)superfamily[J]. Endocr Rev, 1999, 20(6):761-787

[28] Rajaram SJ, Mohan S. Insulin-like growth factor-binding proteins in serum and other biological fluids:regulation and functions[J]. Endocr Rev, 1997, 18(6):801-831

[29] Djiogue S, Nwabo Kamdje AH, Vecchio L, et al. Insulin resistance and cancer: the role of insulin and IGFs[J]. Endocr Relat Cancer, 2013, 20(1):R1-R17

[30] Koyama N, Zhang J, Miyazawa H, et al. Identification of IGFBP-6 as an effector of the tumor suppressor activity of SEMA3B[J]. Oncogene, 2008, 27(51):6581-6589

[31] Kuo YS, Tang YB, Lu TY, et al. IGFBP-6 plays a role as an oncosuppressor gene in NPC pathogenesis through regulating EGR-1 expression[J]. J Pathol, 2010, 222(3):299-309

[32] Kamangar BB, Bobe J. Insulin-like growth factor-binding protein(IGFBP)-1,-2,-3,-4,-5, and-6 and IGFBP-related protein 1 during rainbow trout postvitellogenesis and oocyte maturation:molecular characterization,expression profiles, and hormonal regulation[J]. Endocrinology, 2006, 147(5):2399-2410

[33] Iosef C, Gkourasas T, Jia CY, et al. A functional nuclear localization signal in insulin-like growth factor binding protein-6 mediates its nuclear import[J]. Endocrinology, 2008, 149(3):1214-1226

[34] Iosef C, Vilk G, Gkourasas T, et al. Insulin-like growth factor binding protein-6 (IGFBP-6) interacts with DNAend binding protein Ku80 to regulate cell fate[J]. Cell Signal, 2010, 22(7):1033-1043

[35] Yao R, Wang Y, Lubet RA, et al. Differentially expressed genes associated with mouse lung tumor progression[J]. Oncogene, 2002, 21(37):5814-5821

[36] Grellier P, Berrebi D, Peuchmaur M, et al. The IGF system in neuroblastoma xenografts: focus on IGF-binding protein-6[J]. J Endocrinol, 2002, 172(3):467-476

[37] Oh YS, Kim EJ, Schaffer BS, et al. Synthetic low-calcaemic vitamin $\mathrm{D}(3)$ analogues inhibit secretion of insulinlike growth factor II and stimulate production of insulinlike growth factor-binding protein-6 in conjunction with growth suppression of HT-29 colon cancer cells[J]. Mol Cell Endocrinol, 2001, 183(1/2):141-149

[38] Massoner P, Ladurner Rennau M, Heidegger I, et al. Expression of the IGF axis is decreased in local prostate cancer but enhanced after benign prostate epithelial differentiation and TGF- $\beta$ treatment[J]. Am J Pathol, 2011, 179(6):2905-2919

[39] Lin B, White JT, Wu J, et al. Deep depletion of abundant serum proteins reveals low-abundant proteins as potential biomarkers for human ovarian cancer[J]. Proteomics Clin Appl, 2009, 3(7):853-861

[40] Gunawardana CG, Kuk C, Smith CR, et al.Comprehensive analysis of conditioned media from ovarian cancer cell lines identifies novel candidate markers of epithelial ovarian cancer[J].J Proteome Res,2009,8(10):4705-4713

[41] Cacalano NA, Le D, Paranjpe A, et al. Regulation of IGFBP6 gene and protein is mediated by the inverse expression and function of c-jun $\mathrm{N}$-terminal kinase (JNK) and NFkappaB in a model of oral tumor cells[J]. Apoptosis, 2008, 13(12):1439-1449.

(Received 16 May 2018, Revised 30 May 2018, Accepted 02 June 2018) 